14h., Saturn $4^{\circ}$ S.; Dec. 4d. 04h., Mars $3^{\circ}$ S.; Dec. 1ld. 1lh., Mercury $2^{\circ}$ N.; Dec. 14d. 20h., Venus $3^{\circ}$ N.; Dec. 30d. 2lh., Saturn $4^{\circ}$ S. ; Dec. 31d. 23h., Mars $2^{\circ} \mathrm{S}$. In addition to these conjunctions with the moon, Mercury is in conjunction with Jupiter on Dec. 15d. 02h., Mercury being $0.6^{\circ} \mathrm{S}$. Mercury is a morning star throughout most of the month, rising at $6 \mathrm{~h}$. $04 \mathrm{~m}$., and $7 \mathrm{~h} .12 \mathrm{~m}$. at the beginning and middle of the month respectively; on Dec. 31 the planet rises $12 \mathrm{~m}$. after the sun. Venus, an evening star, is conspicuous in the western sky for some time after sunset as an object of stellar magnitude -3.4 ; about 0.9 of the illuminated portion of the apparent disk is visible during the month. Mars, in the constellation of Leo, can be seen throughout the greater portion of the night, rising at $22 \mathrm{~h} .23 \mathrm{~m} ., 21 \mathrm{~h} .52 \mathrm{~m}$., and $21 \mathrm{~h} .04 \mathrm{~m}$., at the beginning, middle and end of the month, respectively, and is easily recognized from its proximity to Regulus, from which it moves eastward during the month. Jupiter, in conjunction with the sun on Dec. 1, is unfavourably placed for observation until the end of the month, when it is a morning star rising about $1 \frac{3}{4}$ hours before the sun. Saturn, in the constellation of Leo, is well placed for observation, rising at $2 \mathrm{lh} .46 \mathrm{~m} ., 20 \mathrm{~h} .50 \mathrm{~m}$., and $19 \mathrm{~h} .44 \mathrm{~m}$. , at the beginning, middle and end of the month, respectively. Occultations of stars brighter than magnitude 6 are as follows: Dec. 2 d. $04 \mathrm{~h} .53 \cdot 2 \mathrm{~m} ., \lambda$ Canc. $(R)$; Dec. 8 d. 06h. $20 \cdot 5 \mathrm{~m}$., m. Virg. $(R)$; Dec. $25 \mathrm{~d}$. 23h. 40.2m., $x$ Taur. $(D)$; Dec. 26 d. 00h. 09.7m., v Taur. $(D)$. The times are given for Greenwich, and $D$ and $R$ refer to disappearance and reappearance, respectively. The Geminid meteors are active in the early part of the month; they have usually short paths and are not very bright. Winter solstice takes place on Dec. 22d. $17 \mathrm{~h}$.

\section{Chemistry of Penicillin at the University of Oxford}

SIR Robert Robinson writes: "In the very flattering notice published in Nature of November 22, p. 703 , the statement is made that it was in my laboratory that the main facts of the constitution of penicillin were elucidated. This is incorrect, because many of the fundamental observations were made in the laboratory of the School of Pathology. I think a claim for 'Oxford' as a whole has been misunderstood as applying to the Dyson Perrins Laboratory. The collaboration between Drs. E. P. Abraham and E. Chain, Prof. W. Baker and myself was a close partnership, and contributions were made by both laboratories. In the summer of 1943 , penicillamine was synthesized by Dr. and Mrs. J. W. Cornforth, working in the Dyson Perrins Laboratory, but independently, and in the early autumn and later, the attack developed in collaboration with other centres, especially the Imperial College of Science and Technology, in the remainder of 1943. The complex development cannot be easily summarized, but an attempt is made in Chapter 1 (Science, 105, No. 2739, $653 ; 1947)$ of the monograph in course of preparation."

\section{Announcements}

DR. B. P. DEY, director of the Board of Industrial and Research Schemes in Presidency College, Madras, formerly professor of chemistry in that College, has been appointed director of the Indian institute of Science, Bangalore, in succession to Sir J. C. Ghosh, who is now director-general of industry and supply to the Government of India.
THE following appointments in the University of Leeds have been announced: Dr. N. B. Slater, honorary curator of the Cecil Duncombe Observatory; Mr. J. Mars, lecturer in economics; Mr. D. Johnston, lecturer in metallurgy.

THE following appointments in the University of Sheffield have been announced : H. Ferrari, lecturer in mining ; Dr. W. Hume-Rothery, honorary lecturer in the Department of Metallurgy; Prof. H. N. Green, professor of pathology, granted the additional title of director of cancer research. The following resignations have been announced: G. E. Cooke, lecturer in civil engineering; Dr. H. MeIlwain, lecturer in biochemistry.

THE following Colonial Service appointments have been announced : J. S. Blacklock, to be agricultural officer, Sarawak; G. P. Blair, to be agricultural officer, Trinidad; M. H. Breese, to be entomologist, Nyasaland; A. J. P. Goodchild, to be entomologist, Gold Coast; J. L. Jollans, to be agricultural officer, Gold Coast ; E. H. Nichols, to be agricultural officer, Sierra Leone/Gambia; W. A. Wright, to be agricultural officer, Sierra Leone/Gambia; G. E. Crichton, to be assistant conservator of forests, Sierra Leone/Gambia ; Capt. P. B. Finn, to be staff surveyor, Kenya ; J. B. Lyle, to be superintendent of surveys, Palestine; E. F. Martin (deputy director of agriculture, Uganda), to be deputy director of agriculture, Kenya; L. D. E. F. Vesey-Fitzgerald (entomologist, Nigeria), to be senior assistant game warden, Kenya.

A NEW abstract journal, described as "a monthly service of information about developments in technology and research for business men, investors, the Press, educationists and suppliers of services to industry", has appeared under the title Facts for Industry (A. E. Blake, Lower North Dean, Hughenden, High Wycombe, Bucks. Annual subseription, 2 guineas). Abstracts vary in length from about fifty to five hundred words, and are classified by subjects; references to original papers are quoted. The October issue consists of twelve pages including thirty-eight abstracts.

The Hungarian Academy of Sciences has started issuing the following new scientific periodicals, the papers in which are all published in English, French or German : Hungarica Acta Mathematica, Hungarica Acta Physica, Hungarica Acta Chimica, Hungririca Acta Physiologica, Hungarica Acta Biologica, Hungarica Acta Medica. Each volume consists of six fascicles of about 15-17 sheets, and the price has been fixed at 35s. (7 dollars, or 30 Swiss francs) per volume. The Acaderny would welcome the exchange of publications with other scientific institutions, in connexion with which communications should be sent to the office of the Academy, Budapest V, Akadémiautca 2.

Tне Prix Arnold Reymond, provided by the Fondation Charles-Eugène Guye, is offered by the University of Lausanne for a memoir on the tendencies of scientific philosophy during the preceding ten years. The award is made at intervals of between five and ten years, the first award having been made in 1944 to Dr. Pierre Lecomte du Noüy. Memoirs to be considered for the next award, which will amount to at least 1,000 Swiss franes, must reach the Commission du Prix Arnold Reymond, Fondation Charles-Eugène Guye, Secrétariat de l'Université, Lausanne, by January 1, 1951. 